\title{
3 Research Suare \\ Role of Lung Ultrasound in the Management of Patients with Suspected SARS-Cov-2 Infection in the Emergency Department
}

Andrea Boccatonda ( $\sim$ andrea.boccatonda@gmail.com )

Policlinico S.Orsola-Malpighi

Alice Grignaschi

Policlinico S.Orsola-Malpighi

Antonella Lanotte

Policlinico S.Orsola-Malpighi

Fabrizio Giostra

Policlinico S.Orsola-Malpighi

Cosima Schiavone

University of Chieti-Pescara

Maria Teresa Guagnano

University of Chieti-Pescara

Alessio Frisone

University of Chieti-Pescara

Giulio Cocco

University of Chieti-Pescara

\section{Research Article}

Keywords: lung ultrasound, SARS-CoV-2 infection, pneumonia, emergency department

Posted Date: May 13th, 2021

DOI: https://doi.org/10.21203/rs.3.rs-471145/v1

License: (c) (i) This work is licensed under a Creative Commons Attribution 4.0 International License. Read Full License

Version of Record: A version of this preprint was published at Journal of Clinical Medicine on April 7th, 2022. See the published version at https://doi.org/10.3390/jcm11082067. 


\section{Abstract}

Background: the LUS score has been proposed as an optimal scheme for the ultrasound study of the patient with suspected / confirmed COVID-19 pneumonia. The aim of our study was to evaluate the use of lung ultrasound as a diagnostic tool for diagnosing SARS-CoV-2 pneumonia, and to examine the validity of LUS score for the diagnosis of COVID-19 pneumonia, and to correlate with hospitalization rate and 30-days mortality.

Material \& methods: a retrospective analysis was performed on all patients who were referred to the General Emergency Department of the S. Orsola-Malpighi Hospital from April 2020 to May 2020 for symptoms suspected for SARS-CoV-2 infection. The ultrasound examination was based on a common execution scheme called LUS score, as previously described.

Results \& Conclusions: LUS score correlates with the degree of clinical severity and respiratory failure (P/F ratio, Delta (A-a), Delta (A-a) increase). COVID-19 patients with a LUS score > 7 require the use of oxygen support; a value $>10$ is associated with an increased risk of oro-tracheal intubation. The LUS score presents higher values in hospitalized patients, increasing according to the degree of care intensity.

COVID-19 died patients were characterized by a mean LUS score of 11 at presentation to the emergency department. A LUS score value $>7.5$ displays a sensitivity of $83 \%$ and specificity of $89 \%$ against 30 -days mortality in COVID-19 patients. Lung ultrasound seems to be an optimal first level method for pneumonia detection in patients with suspected SARS-CoV-2 infection.

\subsection{Introduction}

Lung ultrasound has significantly increased its importance following the emergence of the SARS-CoV-2 pandemia [1-5]. From the first case reports published since the beginning of 2020, an exponential increase in published works has been achieved [6-11]. Its growing use is due to its characteristics of simplicity, reproducibility and relevance of the information provided in the clinical setting [1-5]. The use of lung ultrasound seems to display the utmost importance as a first level/screening method at the time of the first evaluation of a patient suspected for SARSCoV-2 infection, and secondly as a serial monitoring of the evolution of the disease, especially in patients who cannot be easily mobilized (e.g. intubated and ventilated patient) [1-5].

Several authors suggested specific signs and scores for the study and staging of COVID-19 pneumonia, still not finding a globally accepted scheme $[2-4,11]]$. The LUS score is a score validated in the pre-COVID era in the intensive care setting to monitor ventilated patients [12]; that score has been proposed by several authors as an optimal model / scheme for the ultrasound study of the patient with suspected / confirmed COVID-19 pneumonia $[2-4,11]$.

The aim of our study was to evaluate the use of lung ultrasound as a diagnostic tool for SARS-CoV-2 pneumonia. Secondly, to examine the validity of a pulmonary ultrasound score called "LUS score" for the diagnosis of COVID19 pneumonia, and to correlate with hospitalization rate and in-hospital mortality.

\subsection{Materials And Methods}

\subsection{STUDY DISEGN}


A retrospective analysis of clinical and ultrasound data was performed. An informed consent was obtained from each patients to be involved in the study. The data were obtained from the medical records and the information system. In addition to the ordinary anamnestic and clinical evaluation, lung ultrasound and blood gas analysis were often performed as a first level method for diagnosing COVID-19 pneumonia. Subsequently, the patients were subjected to further tests, with different priority according to the severity of the clinical picture. The study protocol conforms to the ethical guidelines of the 1975 Helsinki Declaration which is reflected in a priori approval by the institution's human research committee. This study was approved. by the local Ethics Committee [551/2020/Oss/AOUBo/ Comitato Etico Indipendente di Area Vasta Emilia Centro (CE-AVEC)].

\subsection{STUDY PATIENTS}

A retrospective analysis was performed on all patients who were referred to the General Emergency Department of the S. Orsola-Malpighi Hospital from April 2020 to May 2020 for symptoms suspected for SARS-CoV-2 infection. All patients were over 18 years of age. The clinical characteristics of the participating subjects are summarized in Tables 1-5. The data analysis was performed subsequently by dividing the patients according to the outcome of the nasopharyngeal swab into COVID-19 positive and COVID-19 negative. Patients with a definitive report of SARSCoV-2 swab and in whom a lung ultrasound was performed were taken into consideration for the subsequent statistical analysis; patients who did not perform those tests were excluded from the final statistical analysis.

\subsection{LUNG ULTRASOUND TECHNIQUE}

Lung ultrasound was performed by a pool of physicians with certified experience in the method. The ultrasound system used was an Esaote Mylab 7. The convex probe was mainly used, and possibly the linear probe for the detailed evaluation of the pleural line. The ultrasound examination was based on a common execution scheme with shared ultrasound semeiotics [12] (Figure 1). The examination involved scanning 6 lung fields per hemithorax (2 anterior, 2 lateral and 2 posterior), for a total of 12 lung fields. The evaluation of the ultrasound signs was based on the scheme previously validated in the intensive care setting [12]; in particular, a score was assigned for each lung field examined (normal = 0 ; non-converging $B$ lines = 1 ; confluent $B$ lines or white lung = 2; consolidation = 3). The sum of the scores of the 12 lung fields examined gave a final result defined as LUS score. The LUS score therefore varies from 0 to 36 . The patient was examined preferably on sitting position; in cases of forced supine position, posterior scans were performed by rotating the patient on the side.

\subsection{Statistical Analysis}

Continuous variables are expressed as mean \pm standard deviation. The Mann - Whitney $U$ test for independent samples was used to compare the quantitative variables between groups. Categorical variables were presented as frequencies and percentages and compared using the chi-square test with Yates correction. The correlations between the variables were examined by determining the Pearsons coefficient. A p value $<0.05$ was considered statistically significant. The ability of LUS score to predict 30-days mortality was assessed by measuring the area under the receiver operating characteristics curve (ROC) (AUC). The best threshold of the ROC curve was chosen using bootstrap analysis and the maximization of the Youden index.

All data was collected and entered into an Excel database (Microsoft Office 2016) and statistical analyzes were performed using SPSS (IBM SPSS Statistics 25 Version, Inc., Chica-go, IL, USA). 


\subsection{Results}

A total of 1826 patients were examined, whose baseline characteristics are summarized in the Table 1 . Based on the result of nasal swab, patients were divided into a COVID-19 positive $(n=617)$ and negative $(n=843)$ groups; the characteristics of which are shown in the table. In 312 cases the nasal swab was not performed; in 11 cases the swab had poor cellularity and in 43 cases the information was not available. Tables 2-4 show respectively the comorbidities, symptoms and vital signs performed in the first emergency department assessment. Tables 5 shows the main blood gas analysis differentiated by COVID-19 nasal swab result.

COVID-19 positive patients came to the emergency department at $5.0 \pm 6.9$ days from the onset of symptoms.

The analysis of COVID-19 positive patients in consideration of the outcome from the emergency department showed that $30 \%$ were discharged, $60.8 \%$ hospitalized in an ordinary ward, $6 \%$ in sub-intensive care, $0.5 \%$ in intensive care, $0.3 \%$ died and $1.6 \%$ transferred to another institution. The analysis of the maximal type of care intensity during the all hospitalization showed that $40.6 \%$ of the COVID-19 patients were discharged, $43.1 \%$ were hospitalized in low-intensity care ward, $6,1 \%$ in the sub-intensive care unit, $5.1 \%$ in the intensive care unit. Considering any oxygen support given to patients throughout the all hospitalization, $16.7 \%$ of COVID-19 positive patients required conventional oxygen therapy, $10.5 \%$ support through Ventimask, $8.6 \%$ oxygen therapy by facial mask and reservoir, $6.5 \%$ continuous positive airway pressure (CPAP), $0.5 \%$ non invasive ventilation (NIV), $0.8 \%$ high-flow nasal cannula (HFNC), 4.4\% orotracheal intubation and invasive ventilation. Considering the whole intrahospital mortality, COVID-19 positive patients had a $15 \%$ mortality rate compared to $8.7 \%$ of COVID-19 negative ( $p$ $<0.001$ ). The 30 -day mortality of COVID-19 patients was $17.9 \%$.

\section{LUNG ULTRASOUND DATA}

A total of 646 lung ultrasound exams were performed (193 in patients with positive swab and 453 in patients with negative swab). Ultrasound showed signs of interstitial disease (B lines) in $72.5 \%$ of COVID-19 positive cases examined. An irregularity of the pleural line was reported in 31.8\% of COVID-19 patients; consolidations were highlighted in $30.5 \%$ of COVID-19 cases; pleural effusion in $8 \%$ of COVID-19 patients. The comparison with the ultrasound data performed on COVID-19 negative patients showed a statistically significant difference for all the analyzed signs (Table 6). The analysis of the mean LUS score values showed a statistically significant difference in the group of patients with positive swab $(3.6 \pm 4.8)$ from those with negative swab $(1.8 \pm 3.6)(p<0.001)$ (Table 7).

In patients with positive nasal swab, the LUS score correlates inversely with $P / F$ ratio $(p<0.001 ; r=-0.56)$ and $S / F$ ratio $(p<0.001 ; r=-0.42)$, and directly with the value of delta $(A-a)(p<0.001 ; r=0.58)$, the value of the increase in delta (A-a) with respect to the expected $(p<0.001 ; r=0.53)$ and with the respiratory rate $(p<0.001 ; r=0.35)$; the LUS score does not correlate with the $\mathrm{pCO}_{2}$ value $(\mathrm{p}=0.06 ; \mathrm{r}=-0.17)$ (Figure 2-4).

Furthermore, LUS score values increase by increasing the level of intensity of care, passing from a mean value of 1.4 in discharged patients to 8.6 in patients who will have hospitalization in intensive care unit (ICU) (Figure 5). Patients who died in the emergency department presented a mean LUS score of $19 \pm 9,8$. Furthermore, the LUS score values increase in agreement with the level of oxygen support provided, going from the mean value of 1.8 in patients who did not require oxygen to the value of 10.0 in patients who will require a orotracheal intubation (OTI) (Figure 6). Considering the group of COVID-19 positive patients, subdivided by survived and died patients at 30 days, there was a statistically significant difference in the LUS score values $(3.0 \pm 4.1$ vs $11.3 \pm 8.4 ; p<0.001)$ 
(Figure 7) (Table 8). The analysis of the ROC curves against 30-days mortality in COVID-19 patients showed an AUC of 0.816 for the LUS score, 0.054 for the P/F ratio, 0.777 for the delta (A-a) increase and 0.825 for the delta (Aa) value. The Youden index calculated on the LUS score curve showed that a value of 7.5 presents a sensitivity of $83 \%$ and specificity of $89 \%$ (Figure 8 ) (Table 9).

\subsection{Discussion}

Our work demonstrates that some clinical features are mostly detected in patients with positive swab (higher age, arterial hypertension and chronic obstructive pulmonary disease). Fever, cough and ageusia are the most specific symptoms of patients with a positive swab.

Considering vital signs, COVID-19 patients were characterized by lower systolic blood pressure, higher body temperature and respiratory rate. The blood gas analysis data showed an alteration of gas exchange in COVID-19 patients, with lower values of P/F ratio, S/F ratio and ROX index, and higher values of delta (A-a). Those data are in agreement with some previous published papers on COVID-19 patients [13,14].

In order to perform an ultrasound quantitative analysis of the lung damage, B-lines were mostly detected $(72.5 \%$ of cases), followed by thickening of the pleural line, consolidations and pleural effusions. By comparing COVID-19 patients to others, all ultrasound signs showed a statistically significant difference, with a greater presence of signs in COVID-19 positive subjects. That finding is in agreement with other previous works $[4-5,7,15-16]$.

Notably, the detection of those signs can be influenced by the clinical phase of the COVID-19 infection; indeed, lung consolidation, a sign of total and complete alteration of the lung parenchyma, is more typical of an advanced stage of the disease, while B lines and pleural line changes seem to be early signs [17-18]. In our work, patients were mainly examined in an early stage of the disease (average of five days from the onset of symptoms), thus justifying the fact that the $B$ lines were the most frequent ultrasound sign.

By comparing the literature, the pleural effusion seems not to be a specific sign of COVID-19 pneumonia, although in our work there is a mild prevalence in the COVID-19 group [19].

In order to provide a quantitative ultrasound assessment, the LUS score scheme was employed. The analysis and comparison of the means of the LUS scores showed that patients with a positive swab had a higher values than the negative ones (3.6 vs 1.8).

The LUS score correlates inversely with the P/F and S / F ratio, and directly with the delta (A-a) and the delta increase to the expected and with the respiratory rate. Therefore those data demonstrate that the LUS score is correlated to the alteration of gas exchange, and thus to pathological changes affecting the lung parenchyma. That data is in agreement with a recent work of Secco et al., reporting similar correlations [20].

In our work, we demonstrated that LUS score values increase in agreement with the level of oxygen support provided; COVID-19 patients requiring orotracheal intubation and mechanical ventilation presented a mean LUS score value of 10.0. Patients treated with mask and reservoir had a mean LUS score of 16; such patients were often suffering from severe respiratory failure without indication to intensive treatment due to age and / or comorbidities. 
Seiler et al., reported that LUS score of 19.5 was identified as cut-off for requirement of invasive mechanical ventilation [21].

By analyzing the LUS score values of the patients according to the type of hospitalization ward, there was a corresponding increase in the ultrasound score as the intensity of care increased. Therefore, a LUS score > 9 was related to patients with sub-intensive / ICU hospitalization.

A recent work by Persona et al., showed a median LUS score of 27.5 in COVID-19 patients with acute respiratory failure at ICU admission [22].

Another work by Tombini et al showed that LUS score $>20$ was presented the best diagnostic accuracy for the primary outcome (endotracheal intubation, no active further management or death); in the same work, a LUS score $<10$ presented the best diagnostic accuracy for the secondary outcome (discharge from the emergency room) [23].

Rubio-Gracia et collegues performed lung ultrasound during the first $72 \mathrm{~h}$ after admission, thus demonstrating that LUS score $>22$ presented the best diagnostic accuracy for in-hospital death and/or admission to the intensive care unit [24].

COVID-19 infection was characterized by higher mortality rate than a non-COVID-19 population (15\% vs $8.7 \%$ ). The higher mortality rate is also confirmed 30 days after admission to the emergency room. The dead patients with positive swab had a higher LUS score mean (11.3) than survived (3.0); A LUS score value greater than 19 detected in the emergency department is related to an higher risk of early death.

The analysis of the ROC curves against 30-days mortality in COVID-19 patients showed an AUC of 0.816 for the LUS score, with a score $>7.5$ presenting a sensitivity of $83 \%$ and specificity of $89 \%$. A recent work by Secco et al, showed that a LUS score $>13$ had a $77.2 \%$ sensitivity and a $71.5 \%$ specificity $(A U C=0.814 ; p<0.001)$ in predicting mortality [20]. In our work we also compared the ROC curve of the Delta (A-a) values found in the blood gas analysis, which showed an AUC comparable to that of the LUS score (AUC $=0.825$ ). This data may suggest how the two methods have a significant diagnostic capacity, which can further improve if performed together; on the other hand, lung ultrasound alone can provide very important information for the clinical management of the patient in an out-of-hospital diagnostic setting.

Several studies reported different LUS score values as predictors of mortality and hospitalization in intensive care [20-25]; those differences are probably due to the different care settings of the various hospitals; in our case, many of the patients examined went to the emergency room few days after the onset of symptoms (mean of 5 days). This made it possible to immediately evaluate patients, often during a non-critical phase of the disease, allowing the best therapy to be set immediately and establishing the best care setting.

Therefore, the LUS score, performed at the time of the first evaluation seems to be a potentially predictor of mortality or clinical worsening in COVID-19 patients.

\subsection{Study Limitations}

There are some limitations in our work. First, the retrospective nature of the study affected the numerical nonuniformity and baseline characteristics of the two comparison groups. Some data were not available for analysis, as they cannot be obtained from the sources consulted. 


\subsection{Conclusions}

Lung ultrasound allows for an optimal assessment of lung parenchyma damage, due to the specific distribution of the disease at the peripheral level [4-5]. Ultrasound also correlates with the degree of clinical severity and respiratory failure. The LUS score correlates with the alteration of the main respiratory gas exchange indices. COVID-19 patients with LUS score $>7$ require the use of oxygen support; a value $>10$ is associated with an increased risk of OTI. The LUS score presents higher values in hospitalized patients, increasing according to the degree of care intensity.

COVID-19 died patients were characterized by a mean LUS score of 11 at presentation to the emergency department. A LUS score value $>7.5$ displays a sensitivity of $83 \%$ and specificity of $89 \%$ against 30 -days mortality in COVID-19 patients. Lung ultrasound seems to be an optimal first level method for pneumonia detection in patients with suspected SARS-CoV-2 infection. Lung ultrasound is an easy-to-perform diagnostic tool providing relevant clinical data, with no contraindications and side effects.

\section{Declarations}

CONFLICT OF INTEREST: The authors declare they have no conflict of interest

Declarations of interest: none

No funding sources

\section{References}

[1] Xing C., Li Q., Du H., Kang W., Lian J., Yuan L. Lung ultrasound findings in patients with COVID-19 pneumonia. Crit Care 2020; 24(1): 174.

[2] Volpicelli G., Gargani L. Sonographic signs and patterns of COVID-19 pneumonia. Ultrasound J 2020; 12(1): 22.

[3] Soldati G., Smargiassi A., Inchingolo R., et al. On Lung Ultrasound Patterns Specificity in the Management of COVID-19 Patients. J Ultrasound Med. 2020 Nov;39(11):2283-2284.

[4] Sofia S., Boccatonda A., Montanari M., et al. Thoracic ultrasound and SARS-COVID-19: a pictorial essay. J Ultrasound 2020; 23(2): 217-21.

[5] Guarracino F., Vetrugno L., Forfori F., et al. Lung, Heart, Vascular, and Diaphragm Ultrasound Examination of COVID-19 Patients: A Comprehensive Approach. J Cardiothorac Vasc Anesth. 2020 Jun 11:S1053-0770(20)30519$\mathrm{X}$.

[6] Montanari M., De Ciantis P., Boccatonda A., et al. Lung ultrasound monitoring of CPAP effectiveness on SARSCoV-2 pneumonia: A case report. Emergency Care Journal; 2020; 16(3).

[7] Lessiani G., Boccatonda A., D'Ardes D., et al. Mondor's Disease in SARS-CoV-2 Infection: A Case of Superficial Vein Thrombosis in the Era of COVID-19. Eur J Case Rep Intern Med. 2020 Sep 1;7(10):001803.

[8] D'Ardes D., Boccatonda A., Rossi I., et al. COVID-19 and RAS: Unravelling an Unclear Relationship. Int J Mol Sci. 2020 Apr 24;21(8):3003. 
[9] Boccatonda A., Ianniello, E., D’Ardes, D., et al. Can Lung Ultrasound be Used to Screen for Pulmonary Embolism in Patients with SARS-CoV-2 Pneumonia? European Journal of Case Reports in Internal Medicine 2020.

[10] Copetti R., Cominotto F., Meduri S., Orso D. The "Survived Lung:" An Ultrasound Sign of "Bubbly Consolidation" Pulmonary Infarction. Ultrasound Med Biol 2020.

[11] Volpicelli G., Lamorte A., Villén T. What's new in lung ultrasound during the COVID-19 pandemic. Intensive Care Med 2020: 1-4.

[12] Bouhemad B., Mongodi S., Via G., Rouquette I. Ultrasound for "lung monitoring" of ventilated patients. Anesthesiology. 2015 Feb;122(2):437-47.

[13] Wang D., Hu B., Hu C., et al. Clinical characteristics of 138 hospitalized patients with 2019 novel coronavirusinfected pneumonia in Wuhan, China. JAMA 2020; 323:1061-1069.

[14] Weiss P., Murdoch D. R. Clinical course and mortality risk of severe COVID-19. Lancet 2020; 395(10229): 10145.

[15] Lomoro P., Verde F., Zerboni F., et al. COVID-19 pneumonia manifestations at the admission on chest ultrasound, radiographs, and CT: single-center study and comprehensive radiologic literature review. Eur J Radiol Open 2020; 7: 100231.

[16] Yang Y., Huang Y., Gao F., Yuan L., Wang Z. Lung ultrasonography versus chest CT in COVID-19 pneumonia: a two-centered retrospective comparison study from China. 2020: 1-3.

[17] Smith MJ., Hayward SA., Innes SM., Miller ASC. Point-of-care lung ultrasound in patients with COVID-19 - a narrative review. Anaesthesia. 2020 Aug;75(8):1096-1104.

[18] Siddiqi HK., Mehra MR. COVID-19 illness in native and immunosuppressed states: A clinical-therapeutic staging proposal. J Heart Lung Transplant. 2020;39(5):405-407.

[19] Zhan N., Guo Y., Tian S., et al. Clinical characteristics of COVID-19 complicated with pleural effusion. BMC Infect Dis. 2021 Feb 15;21(1):176.

[20] Secco G., Delorenzo M., Salinaro F., et al. Lung ultrasound presentation of COVID-19 patients: phenotypes and correlations. Intern Emerg Med. 2021 Mar 1.

[21] Seiler C., Klingberg C., Hårdstedt M. Lung Ultrasound for Identification of Patients Requiring Invasive Mechanical Ventilation in COVID-19. J Ultrasound Med. 2021 Jan 26.

[22] Persona P., Valeri I., Zarantonello F., et al. Patients in intensive care unit for COVID-19 pneumonia: the lung ultrasound patterns at admission and discharge. An observational pilot study. Ultrasound J. 2021 Feb 24;13(1):10.

[23] Tombini V., Di Capua M., Capsoni N., et al. Risk Stratification in COVID-19 Pneumonia - Determining the Role of Lung Ultrasound. Ultraschall Med. 2021 Feb 18.

[24] Rubio-Gracia J., Giménez-López I., Garcés-Horna V., et al. Point-of-care lung ultrasound assessment for risk stratification and therapy guiding in COVID-19 patients. A prospective non-interventional study. Eur Respir J. 2021 
Feb 25:2004283.

[25] Bosso G., Allegorico E., Pagano A. et al. Lung ultrasound as diagnostic tool for SARS-CoV-2 infection. Intern Emerg Med 2020.

\section{Tables}

Table 1. Patients differentiation by SARS-CoV-2 nasal swab result; data are preser

\begin{tabular}{l|l} 
ALI PATIENTS & $\mathrm{N}=1826$ \\
Positive nasal swab & $617(33,8 \%)$ \\
\hline Negative nasal swab & $843(46,2 \%)$ \\
\hline Nasal swab not performed & $312(17,1 \%)$ \\
\hline Nasal swab with poor cellularity & $11(0,6 \%)$ \\
\hline Data not available & $43(2,3 \%)$
\end{tabular}

Table 2. Comorbidities of study patients; CKD: chronic kidney disease; COPD: chronic obstructive pulmonary disease. Categorical variables are presented as frequencies and percentages.

\begin{tabular}{l|l|l|l|l} 
& $\begin{array}{l}\text { All Patients } \\
(1826)\end{array}$ & $\begin{array}{l}\text { COVID-19 } \\
(617)\end{array}$ & $\begin{array}{l}\text { COVID-19- value } \\
(843)\end{array}$ & $453(53,7 \%)$ \\
Female sex & $957(52,4 \%)$ & $301(48,8 \%)$ & $261(31 \%)$ & 0,000 \\
\hline Hypertension & $561(30,7 \%)$ & $238(38,6)$ & $77(9,1 \%)$ & 0,168 \\
\hline Diabetes & $171(9,4 \%)$ & $69(11,2 \%)$ & $89(10,5 \%)$ & 0,000 \\
\hline COPD & $165(9,0 \%)$ & $66(10,7 \%)$ & $42(5 \%)$ & 0,200 \\
\hline Asthma & $70(3,8 \%)$ & $18(2,9 \%)$ & $40(4,7 \%)$ & 0,242 \\
\hline Other lung disease & $67(3,7 \%)$ & $18(2,9 \%)$ & $85(10,1 \%)$ & 0,002 \\
\hline $\begin{array}{l}\text { Ischaemic cardiac } \\
\text { disease }\end{array}$ & $148(8,1 \%)$ & $49(7,9 \%)$ & $65(7,7 \%)$ & 0,003 \\
\hline Cancer active & $101(5,5 \%)$ & $25(4,1 \%)$ & $62(7,4 \%)$ & 0,068 \\
\hline CKD & $122(6,7 \%)$ & $48(7,8 \%)$ & $45(5,3 \%)$ & 0,055 \\
\hline Stroke & $90(4,9 \%)$ & $36(5,8 \%)$ & $12(1,4 \%)$ & 0,293
\end{tabular}


Table 3. Main symptoms reported by patients on presentation to the emergency department; categorical variables are presented as frequencies and percentages.

\begin{tabular}{l|l|l|l|l} 
Symptoms & All Patients (1826) & COVID-19+ (617) & COVID-19 - (843) & P value \\
Fever & $1325(72,6 \%)$ & $498(80,7 \%)$ & $567(67,3 \%)$ & 0,000 \\
\hline Dyspnea & $641(35,1 \%)$ & $243(39,4 \%)$ & $283(33,6 \%)$ & 0,305 \\
\hline Cough & $803(44,0 \%)$ & $305(49,4 \%)$ & $324(38,4 \%)$ & 0,000 \\
\hline Conjunctivitis & $42(2,3 \%)$ & $8(1,3 \%)$ & $27(3,2 \%)$ & 0,163 \\
\hline Pharyngodynia & $203(11,1 \%)$ & $38(6,2 \%)$ & $107(12,7 \%)$ & 0,000 \\
\hline Headache & $225(12,3 \%)$ & $55(8,9 \%)$ & $99(11,7 \%)$ & 0,000 \\
\hline Asthenia & $317(17,4 \%)$ & $112(18,2 \%)$ & $141(16,7 \%)$ & 0,477 \\
\hline Myalgia/arthralgia & $219(12,0 \%)$ & $76(12,3 \%)$ & $98(11,6 \%)$ & 0,900 \\
\hline Diarrhea & $300(16,4 \%)$ & $86(13,9 \%)$ & $146(17,3 \%)$ & 0,071 \\
\hline Anosmia & $73(4,0 \%)$ & $30(4,9 \%)$ & $25(3,0 \%)$ & 0,283 \\
\hline Ageusia & $146(8,0 \%)$ & $56(9,1 \%)$ & $53(6,3 \%)$ & 0,033 \\
\hline Chest pain & $98(5,4 \%)$ & $16(2,6 \%)$ & $51(6,0 \%)$ & 0,016
\end{tabular}

Table 4. Age and vital signs of patients on emergency department admission; SBP, systolic blood pressure; DBP, dyastolic blood pressure; MAP, mean arterial pressure; CR, cardiac rate; RR, respiratory rate. Continuous variables are expressed as mean \pm standard deviation. 


\begin{tabular}{l|l|l|l|l} 
& All & COVID- & COVID- & P \\
& patients & $19+$ & $19-$ & value \\
& $(1826)$ & $(617)$ & $(843)$ & \\
Age (years) & $57,0 \pm$ & $62,3 \pm$ & $57,3 \pm$ & 0,000 \\
& 21,2 & 19,3 & 21,7 & \\
\hline SBP & $128,3 \pm$ & 125,9 & $129,4 \pm$ & 0,032 \\
$(\mathrm{mmHg})$ & 21,0 & $\pm 20,2$ & 22,2 & \\
\hline DBP & $75,5 \pm$ & $74,6 \pm$ & $75,6 \pm$ & 0,159 \\
$(\mathrm{mmHg})$ & 12,8 & 12,4 & 13,4 & \\
\hline MAP & $68,4 \pm$ & $76,7 \pm$ & $68,8 \pm$ & 0,118 \\
$(\mathrm{mmHg})$ & 42,4 & 36,1 & 43,2 & \\
\hline CR (bpm) & $88,2 \pm$ & $88,9 \pm$ & $89,0 \pm$ & 0,95 \\
& 16,9 & 16,7 & 17,1 & \\
\hline RR (a/min) & $18,8 \pm$ & $19,7 \pm$ & $18,7 \pm$ & 0,000 \\
& 5,2 & 5,5 & 5,2 & \\
\hline Temperature & $36,9 \pm$ & $37,1 \pm$ & $36,9 \pm 0,7$ & 0,000 \\
$\left({ }^{\circ} \mathrm{C}\right)$ & 0,7 & 0,8 & &
\end{tabular}

Table 5. Respiratory and blood gas analytical data found in the emergency department; S/F: $\mathrm{SpO}_{2} / \mathrm{FiO}_{2} ; \mathrm{P} / \mathrm{F}: \mathrm{pO}_{2} / \mathrm{FiO}_{2}$; ROX index: $\mathrm{SpO}_{2} / \mathrm{FiO}_{2}$ to respiratory rate. Continuous variables are expressed as mean \pm standard deviation. 


\begin{tabular}{l|l|l|l|l} 
& $\begin{array}{l}\text { All Patients } \\
(1826)\end{array}$ & $\begin{array}{l}\text { COVID-19 } \\
(617)\end{array}$ & $\begin{array}{l}\text { COVID-19 } \\
(843)\end{array}$ & $\begin{array}{l}\text { P } \\
\text { value }\end{array}$ \\
$\mathrm{S} / \mathrm{F}$ & $449,9 \pm 59,0$ & $440,8 \pm 69,1$ & $453,3 \pm 53,3$ & 0,000 \\
\hline $\mathrm{pCO2}(\mathrm{mmHg})$ & $35,0 \pm 8,5$ & $33,7 \pm 6,7$ & $35,9 \pm 10,3$ & 0,000 \\
\hline $\mathrm{P} / \mathrm{F}$ & $386,6 \pm 157,8$ & $348,2 \pm 104,2$ & $\begin{array}{l}400,0 \pm \\
202,3\end{array}$ & 0,000 \\
\hline $\begin{array}{l}\text { HCO3 } \\
(\mathrm{mmol} / \mathrm{L})\end{array}$ & $24,7 \pm 3,2$ & $24,4 \pm 3,8$ & $24,7 \pm 2,6$ & 0,45 \\
\hline LAC (mmol/L) & $1,3 \pm 1,3$ & $1,4 \pm 1,6$ & $1,2 \pm 0,9$ & 0,19 \\
\hline DELTA (A-a) & $23,4 \pm 33,4$ & $32,2 \pm 21,7$ & $20,2 \pm 42,6$ & 0,000 \\
\hline $\begin{array}{l}\text { DELTA (A-a) } \\
\text { expected }\end{array}$ & $18,0 \pm 5,5$ & $19,5 \pm 4,8$ & $18,3 \pm 5,4$ & 0,000 \\
\hline $\begin{array}{l}\text { DELTA (A-a) } \\
\text { increase }\end{array}$ & $0,29 \pm 2,0$ & $0,6 \pm 1,1$ & $0,0 \pm 2,8$ & 0,000 \\
\hline ROX index & $24,9 \pm 7,7$ & $23,7 \pm 7,6$ & $25,2 \pm 7,6$ & 0,000
\end{tabular}

Table 6. Findings of the four main pathological lung ultrasound signs and comparison between the two groups; Categorical variables are presented as frequencies and percentages and compared using the chi-square test with Yates correction.

\begin{tabular}{l|l|l|l} 
LUNG ULTRASOUND & $\begin{array}{l}\text { COVID-19 } \\
(193)\end{array}$ & $\begin{array}{l}\text { COVID-19 } \\
(453)\end{array}$ & $\begin{array}{l}\text { P } \\
\text { value }\end{array}$ \\
B LINES & $140(72,5 \%)$ & $210(46,3 \%)$ & $<0,001$ \\
\hline $\begin{array}{l}\text { PLEURAL LINE } \\
\text { IRREGULARITY }\end{array}$ & $61(31,8 \%)$ & $98(21,6 \%)$ & $<0,001$ \\
\hline CONSOLIDATION & $59(30,5 \%)$ & $94(20,7 \%)$ & $<0,001$ \\
\hline PLEURAL EFFUSION & $16(8,2 \%)$ & $32(7,0 \%)$ & 0,040
\end{tabular}

Table 7. LUS score values differentiated by SARS-CoV-2 nasal swab result; continuous variables are expressed as mean \pm standard deviation. 


\begin{tabular}{l|l|l|l|l} 
& $\begin{array}{l}\text { All Patients } \\
(646)\end{array}$ & $\begin{array}{l}\text { COVID }-19+ \\
(193)\end{array}$ & $\begin{array}{l}\text { COVID-19 } \\
-(453)\end{array}$ & $\begin{array}{l}\text { P } \\
\text { value }\end{array}$ \\
$\begin{array}{l}\text { LUS } \\
\text { score }\end{array}$ & $2,0 \pm 3,7$ & $3,6 \pm 4,8$ & $1,8 \pm 3,6$ & $<0,001$
\end{tabular}

Table 8. Comparison of blood gas analysis and ultrasound data between dead and survived COVID-19 patients.

\begin{tabular}{|c|c|c|c|}
\hline $\mathrm{pCO}_{2}$ & $\begin{array}{l}\mathrm{DEAD} \\
32,5 \pm \\
6,8\end{array}$ & $\begin{array}{l}\text { SURVIVED } \\
34,0 \pm 6,6\end{array}$ & $\begin{array}{l}\text { P } \\
\text { value } \\
0,046\end{array}$ \\
\hline $\mathrm{P} / \mathrm{F}$ & $\begin{array}{l}255,7 \pm \\
85,7\end{array}$ & $\begin{array}{l}369,5 \pm \\
94,8\end{array}$ & $<0,001$ \\
\hline $\begin{array}{l}\text { DELTA } \\
(\mathrm{A}-\mathrm{a})\end{array}$ & $\begin{array}{l}47,8 \pm \\
19,3\end{array}$ & $\begin{array}{l}28,8 \pm \\
19,4\end{array}$ & 0,018 \\
\hline $\begin{array}{l}\text { LUS } \\
\text { SCORE }\end{array}$ & $\begin{array}{l}11,3 \pm \\
8,4\end{array}$ & $3,0 \pm 4,1$ & $<0,001$ \\
\hline
\end{tabular}

Table 9. Data derived by ROC analysis for 30-days mortality in COVID-19 patients; AUC, area under the curve; IC, confidence interval.

\begin{tabular}{|l|l|l|l|l|}
\hline & AUC & STD ERROR & Asymptotic sig. & IC 95\% \\
\hline LUS score & 0,816 & 0,120 & 0,010 & $0,581-1,000$ \\
\hline P/F & 0,054 & 0,032 & 0,000 & $0,000-0,117$ \\
\hline DELTA (A-a) & 0,825 & 0,127 & 0,008 & $0,575-1,000$ \\
\hline DELTA increase & 0,777 & 0,081 & 0,023 & $0,619-0,936$ \\
\hline
\end{tabular}

\section{Figures}




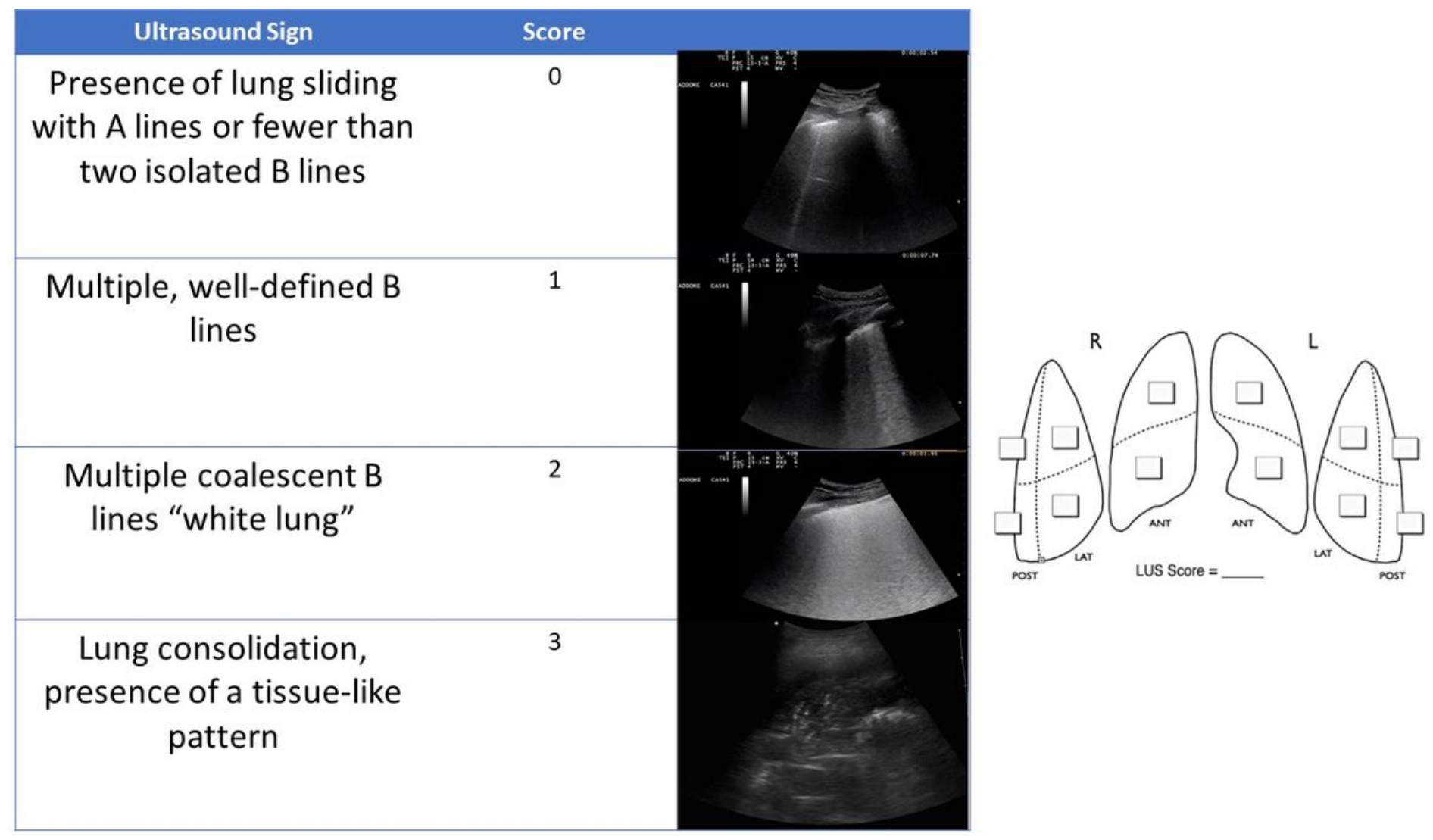

\section{Figure 1}

The sum of the number of the 12 lung fields examined provides a final result (LUS score); the LUS score therefore ranges from 0-36. The patient was examined preferentially on a sitting position; in case of forced supine position, posterior scans were performed by rolling the patient on the side. Figure adapted by Bouhemad B et al; Ultrasound for "Lung Monitoring" of Ventilated Patients. Anesthesiology 2015; 122:437-447 




Figure 2

Correlation between LUS score and Delta (A-a) in COVID-19 patients. 


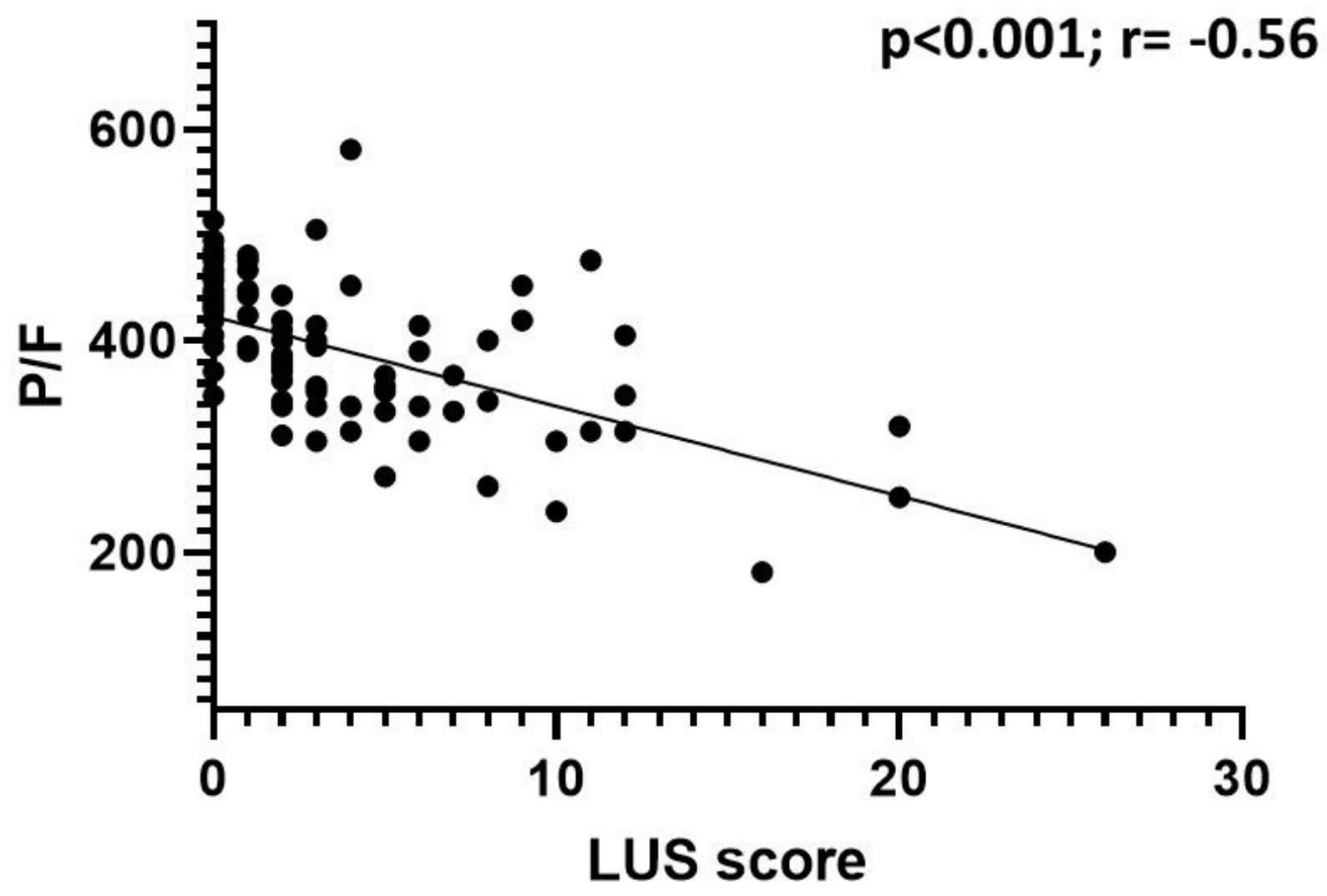

Figure 3

Correlation between LUS score and P/F ratio in COVID-19 patients. 


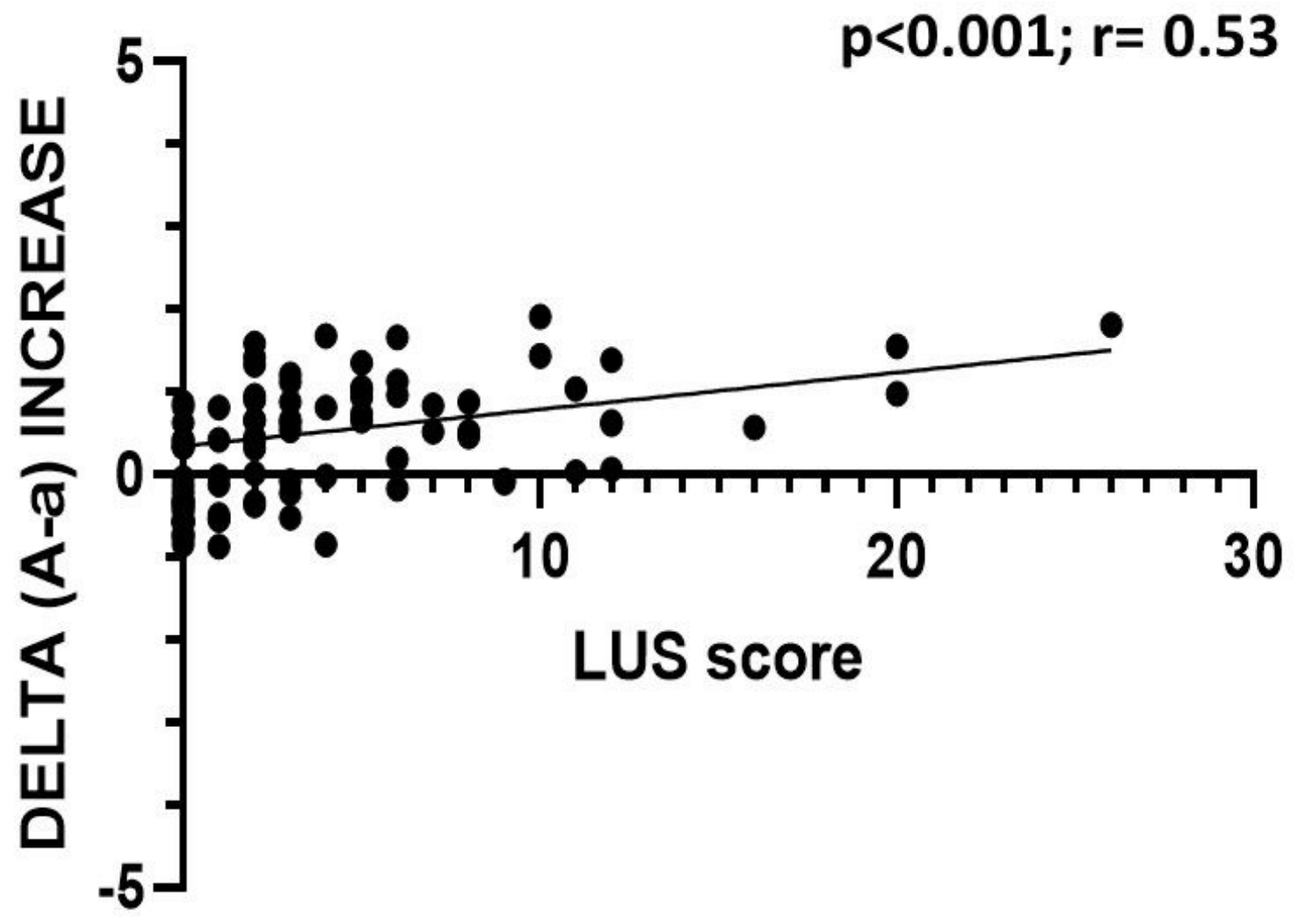

Figure 4

Correlation between LUS score and Delta (A-a) increase in COVID-19 patients. 


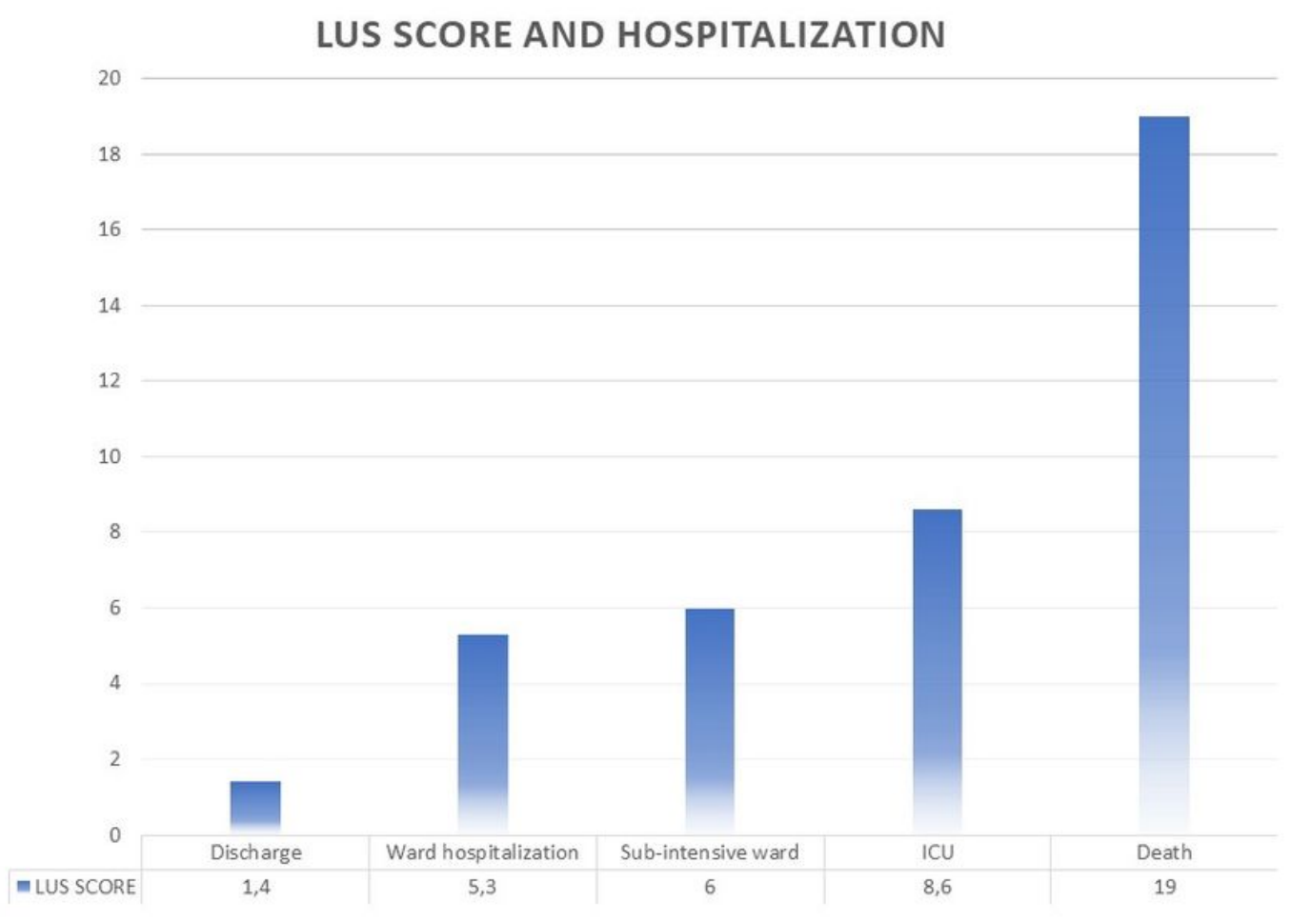

Figure 5

LUS score values divided by type of oxygen support; the values are expressed as means.

\section{LUS SCORE AND MAXIMUM OXYGEN SUPPORT}

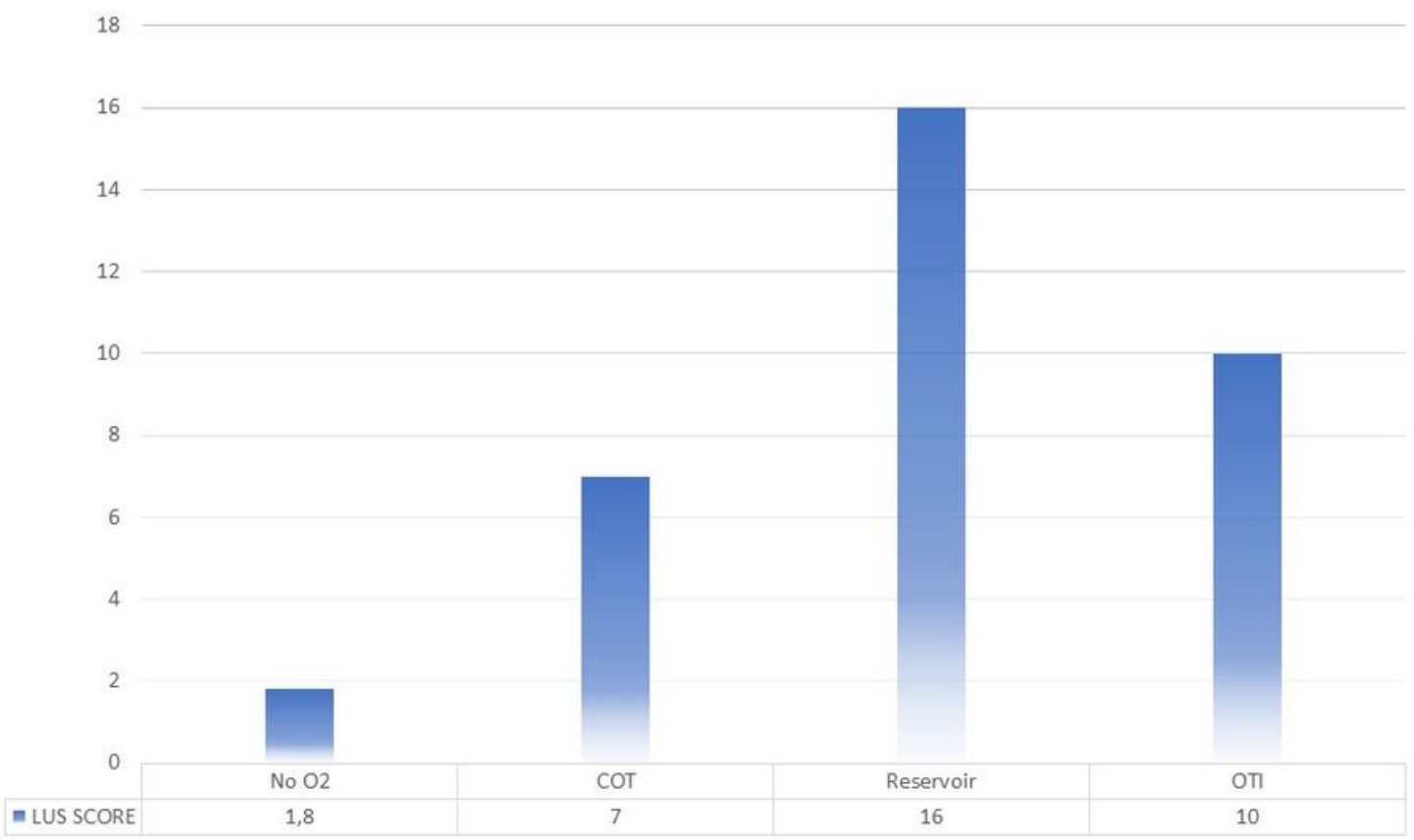

Figure 6 
LUS score values divided by type of hospitalization; the values are expressed as means.

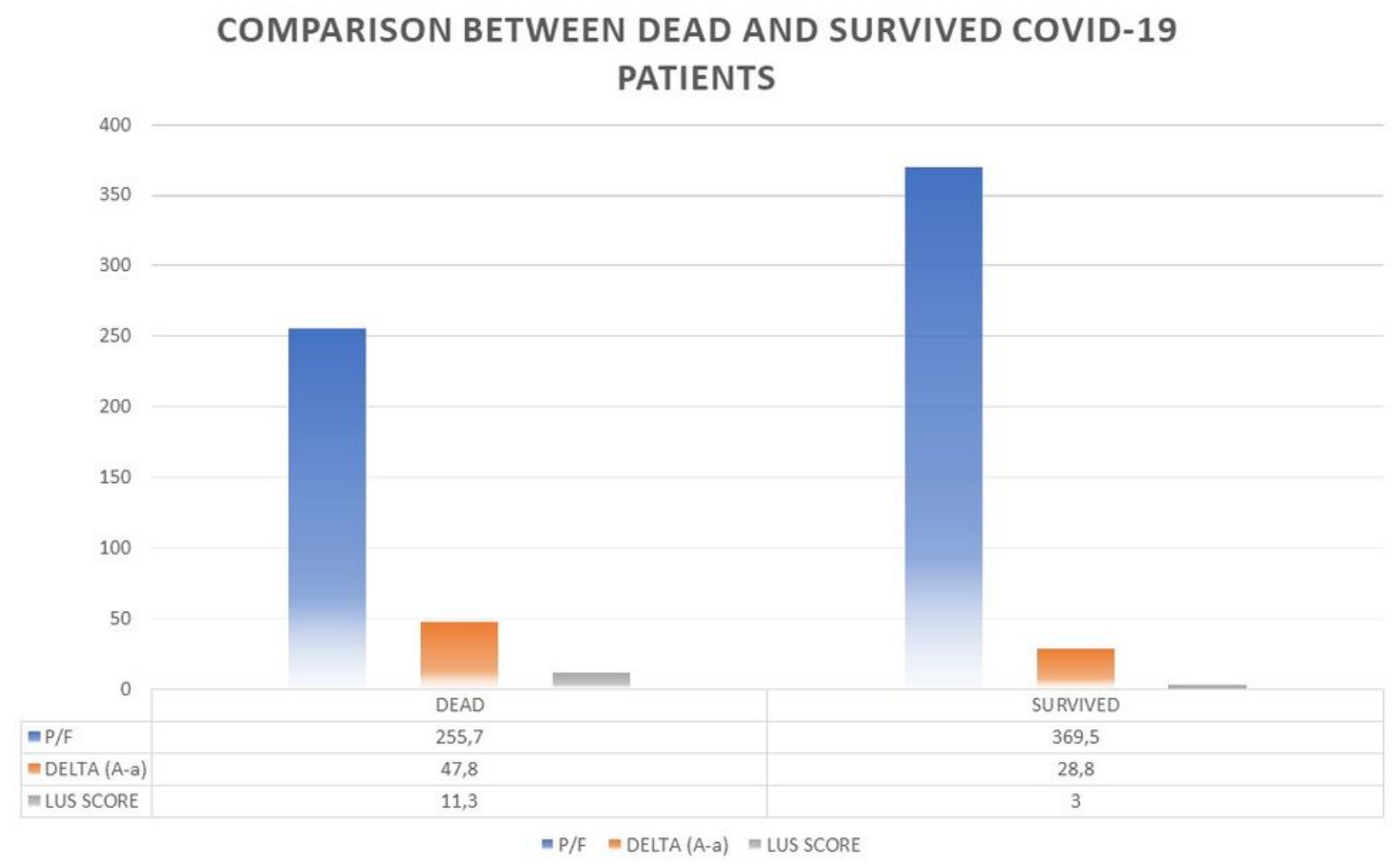

Figure 7

Comparison between dead vs survived COVID-19 patients; the values are expressed as means.

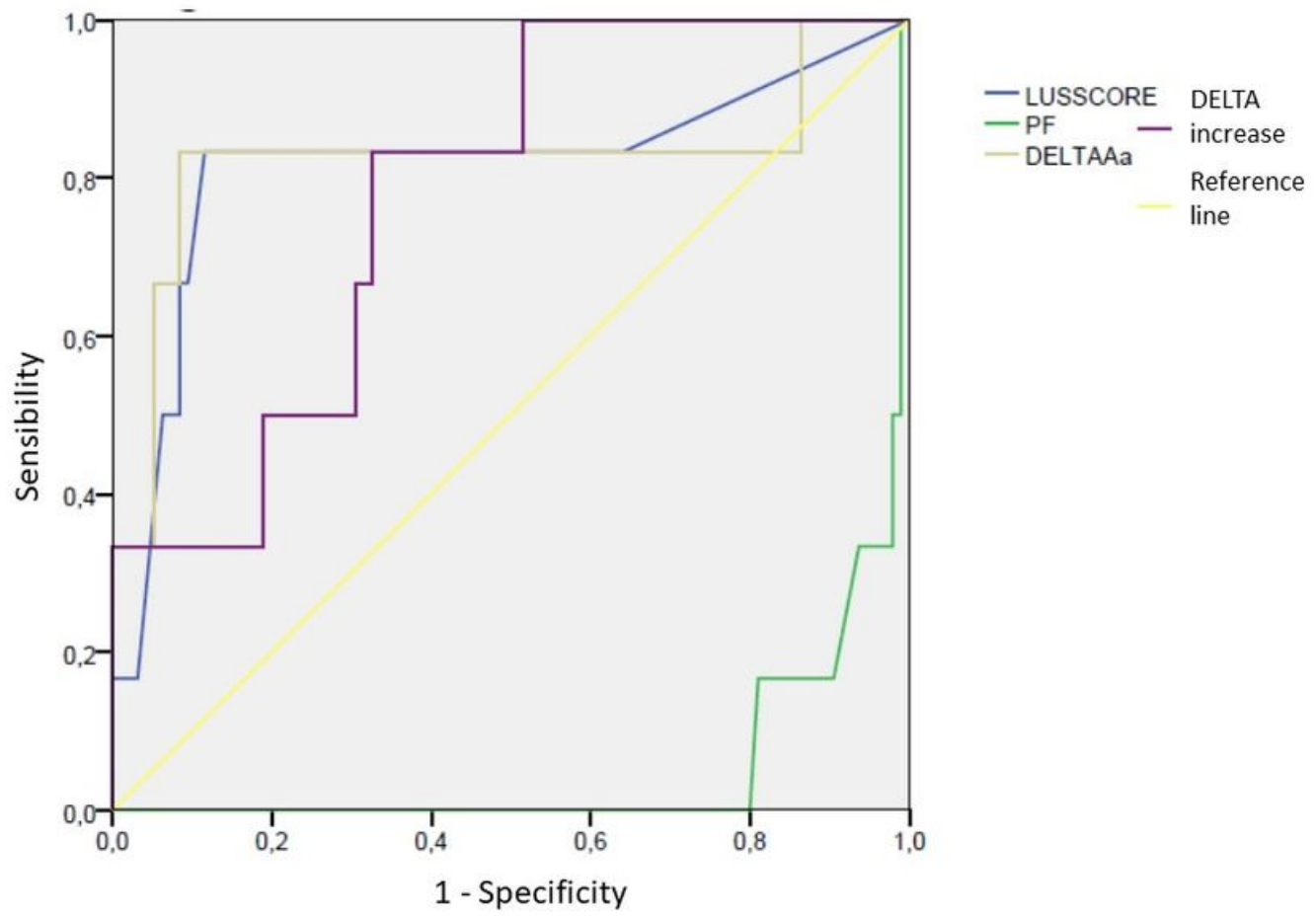




\section{Figure 8}

Comparison of ROC curves of LUS score, P / F ratio, Delta (A-a) and Delta (A-a) increase for 30-day mortality of COVID-19 patients 